\title{
Research Article \\ Effect of Pretreatment with Sulfuric Acid on Catalytic Hydrocracking of Fe/AC Catalysts
}

\author{
Ruiyu Wang, ${ }^{1}$ Fei Wang, ${ }^{2}$ and Ling Liu ${ }^{1}$ \\ ${ }^{1}$ Key Laboratory of Coal-Based $\mathrm{CO}_{2}$ Capture and Geological Storage of Jiangsu Province, China University of Mining \& Technology, \\ Xuzhou, Jiangsu 221008, China \\ ${ }^{2}$ School of Chemical Engineering and Technology, China University of Mining \& Technology, Xuzhou, Jiangsu 221116, China
}

Correspondence should be addressed to Ruiyu Wang; wangruiyu@cumt.edu.cn

Received 1 October 2017; Accepted 13 November 2017; Published 1 December 2017

Academic Editor: Xun Hu

Copyright (C) 2017 Ruiyu Wang et al. This is an open access article distributed under the Creative Commons Attribution License, which permits unrestricted use, distribution, and reproduction in any medium, provided the original work is properly cited.

Activated carbon (AC) was modified by $\mathrm{H}_{2} \mathrm{SO}_{4}$ and used as a support for catalyst. The $\mathrm{Fe}_{2} \mathrm{~S}_{3} / \mathrm{AC}$ - $\mathrm{T}$ catalyst was prepared by deposition-precipitation method and used to catalyze hydrocracking of coal-related model compound, di(1-naphthyl)methane (DNM). The properties of catalyst were studied by $\mathrm{N}_{2}$ adsorption-desorption, X-ray diffraction, and scanning electron microscopy. The result showed that ferric sulfate and acidic centers had synergetic effect on hydrocracking of DNM when using $\mathrm{Fe}_{2} \mathrm{~S}_{3} / \mathrm{AC}-\mathrm{T}$ as catalyst, the optimal loading of $\mathrm{Fe}$ is $9 \mathrm{wt} . \%$. Hydroconversion of the extraction residue from Guizhou bituminous coal was also studied using $\mathrm{Fe}_{2} \mathrm{~S}_{3} / \mathrm{AC}-\mathrm{T}$ as the catalyst. The reaction was conducted in cyclohexane under $0.8 \mathrm{Mpa}$ of initial hydrogen pressure at $310^{\circ} \mathrm{C}$. The reaction mixture was extracted with petroleum ether and analyzed by GC/MS. Amounts of organic compounds which fall into the categories of homologues of benzene and naphthalene were detected. It suggested that the catalyst could effectively catalyze the cleavage of C-C-bridged bonds.

\section{Introduction}

As an important chemical process, direct coal liquefaction (DCL) could be a feasible option to directly convert coals into liquid fuels or chemicals $[1,2]$. Nowadays, rapid decrease of petroleum stresses the importance of coals for covering the shortage of organic chemical feedstock $[3,4]$. Compared to the existing DCL performed at high temperatures, low-temperature DCL should be more promising in consideration of the fact that the formation of gaseous products and coke can be considerably reduced at low temperatures [5-7].

Catalyst is one of key issues in DCL process. Considerable efforts [8-15] have been contributed to the catalytic performances of metal-based ( $\mathrm{Fe}$ and $\mathrm{Ni}$ ) catalysts for DCL or to the reactions of coal-related model compounds. It is generally accepted that catalysts can significantly promote coal pyrolysis by reducing the pyrolysis activation energy and the formation of active hydrogen atoms (AHAs) by facilitating $\mathrm{H}_{2}$ dissociation $[16,17]$. The cleavage of $\mathrm{C}-\mathrm{C}$ bridged bonds in coals, which is very important for DCL, begins with the secondary distribution of AHAs in the whole reaction system $[9,15,17]$. Iron sulfides are commonly used catalyst for DCL because of their easy availability. By literatures $[18,19], \mathrm{FeS}_{2}$ thermolysis to $\mathrm{Fe}_{1-\mathrm{x}} \mathrm{S}$ and $\mathrm{FeS}_{2}$ regenerated from the reaction of $\mathrm{Fe}_{1-x} \mathrm{~S}$ with $\mathrm{H}_{2} \mathrm{~S}$ facilitates the continuous formation of AHAs. In another word, the cycle of $\mathrm{FeS}_{2}$ decomposition and regeneration contributes to its catalysis in the reactions of DCL.

Although the iron-based catalysts are successfully used in industrial processes of DCL, their efficiency is still quite low. Solid acids are commonly catalyst for cracking reactions, and the corresponding acidic sites are active for the cleavage of C-C-bridged bonds [12-14, 20, 21]. If combined with acidic centers, the Fe-based catalyst could exhibit an improved catalytic performance in DCL process. Therefore, we prepared an iron sulfide-supported catalyst, the activated carbon (AC) which was modified by $\mathrm{H}_{2} \mathrm{SO}_{4}$ was used as support, and the catalysts were used to catalyze hydrocracking of a coal-related model compound (DNM) and hydroconversion of the extraction residue of a bituminous coal. 


\section{Experiments}

2.1. Preparation of Catalyst. Guizhou bituminous coal (GBC) was collected from Guizhou province, China. It was pulverized to pass a 200 -mesh sieve followed by desiccation in a vacuum oven at $80^{\circ} \mathrm{C}$ before use. All of chemical reagents used in the experiments are commercially obtained.

$3 \mathrm{~g}$ activated carbon (AC) was placed in a beaker, and $10 \mathrm{~mL} \mathrm{H}_{2} \mathrm{SO}_{4}(2 \mathrm{~mol} / \mathrm{L})$ was added. The mixture was disposed by ultrasound by placing the beaker into an ultrasonic oscillator for $3 \mathrm{~min}$ and then kept overnight. The obtained mixture was dried under drier at $80^{\circ} \mathrm{C}$ for $6 \mathrm{~h}$. The product obtained was denoted as AC-T ( $\mathrm{T}$ means treated carrier), and the corresponding amount of acid was $2.0 \mathrm{mmol} / \mathrm{g}$, which was measured via neutral drip reaction with $\mathrm{NaOH}$ solution.

A certain amount of $\mathrm{Fe}_{2}\left(\mathrm{SO}_{4}\right)_{3}(0.34 \mathrm{~g}, 0.59 \mathrm{~g}, 0.86 \mathrm{~g}$, $1.16 \mathrm{~g}$, and $1.48 \mathrm{~g}$ ) and the corresponding amount of $\mathrm{Na}_{2} \mathrm{~S} \cdot 9 \mathrm{H}_{2} \mathrm{O}(0.612 \mathrm{~g}, 1.602 \mathrm{~g}, 1.55 \mathrm{~g}, 2.09 \mathrm{~g}$, and $2.66 \mathrm{~g}$ ) were dissolved in $50 \mathrm{~mL}$ deionized water, respectively. Under stirring, both the $\mathrm{Na}_{2} \mathrm{~S}$ and $\mathrm{Fe}_{2}\left(\mathrm{SO}_{4}\right)_{3}$ aqueous solution were continuously dropped to $10 \mathrm{~mL}$ deionized water at the same rate. When the reactions were completed, the $3 \mathrm{~g} \mathrm{AC-T}$ support was added. The mixture was kept stirring for 10 min followed by filtration, and the filter cake was dried at $100^{\circ} \mathrm{C}$ for $2 \mathrm{~h}$. The product obtained was calcined at $300^{\circ} \mathrm{C}$ and held at the temperature for $2 \mathrm{~h}$ under a protection of $\mathrm{N}_{2}$ flow. The obtained catalyst was denoted as $\mathrm{Fe}_{2} \mathrm{~S}_{3}$ / $\mathrm{AC}-\mathrm{T}(x)$, where $x$ represents the weight percentage of $\mathrm{Fe}$ in catalyst.

For unmodified AC as support, the catalyst prepared at the same conditions was denoted as $\mathrm{Fe}_{2} \mathrm{~S}_{3} / \mathrm{AC}$.

2.2. Characterization of Catalyst. $\mathrm{N}_{2}$ adsorption-desorption isotherms were measured with a Bayer BELSORP-max instrument. Specific surface area (SSA), total pore volume (TPV), and average pore diameter (APD) of the samples were calculated from the isotherms via t-plot, $\mathrm{BJH}$, and $\mathrm{HK}$ methods, respectively. Morphology of the samples and the corresponding elemental distribution on the surface were characterized using a FEI Quanta 250 scanning electron microscope (SEM) coupled with an energy-dispersive spectrometer (EDS). The X-ray diffraction pattern was recorded on a Burker D8 ADVANCE diffractometer with a scanning rate of $4^{\circ} / \mathrm{min}$ at $2 \theta$ of 10 to $80^{\circ}$, using a $\mathrm{Cu}$ ka radiation $(\lambda=0.154 \mathrm{~nm})$ at $40 \mathrm{kV}$ and $40 \mathrm{~mA}$.

2.3. Di(1-naphthyl)methane Hydrocracking. Di(1-naphthyl)methane (DNM, $1 \mathrm{mmol})$, catalyst $(0.4 \mathrm{~g})$, and cyclohexane $(30 \mathrm{~mL})$ were put into a $60 \mathrm{~mL}$ stainless, magnetically stirred autoclave. After replacing the air with hydrogen for 3 times, the autoclave was pressurized to $0.8 \mathrm{MPa}$ and heated to an indicated temperature in $15 \mathrm{~min}$. Under stirring at a rate of $200 \mathrm{r} / \mathrm{m}$, the reaction was conducted for $1 \mathrm{~h}$. Then the autoclave was cooled to room temperature in an ice-water bath. The gaseous reaction mixture was taken out from the autoclave and quantified using a gas chromatography (9790, Zhejiang Fuli, China).

2.4. GBC Residue Hydroconversion. $2 \mathrm{~g}$ GBC and $50 \mathrm{~mL}$ acetone were put into a $100 \mathrm{~mL}$ stainless, magnetically stirred

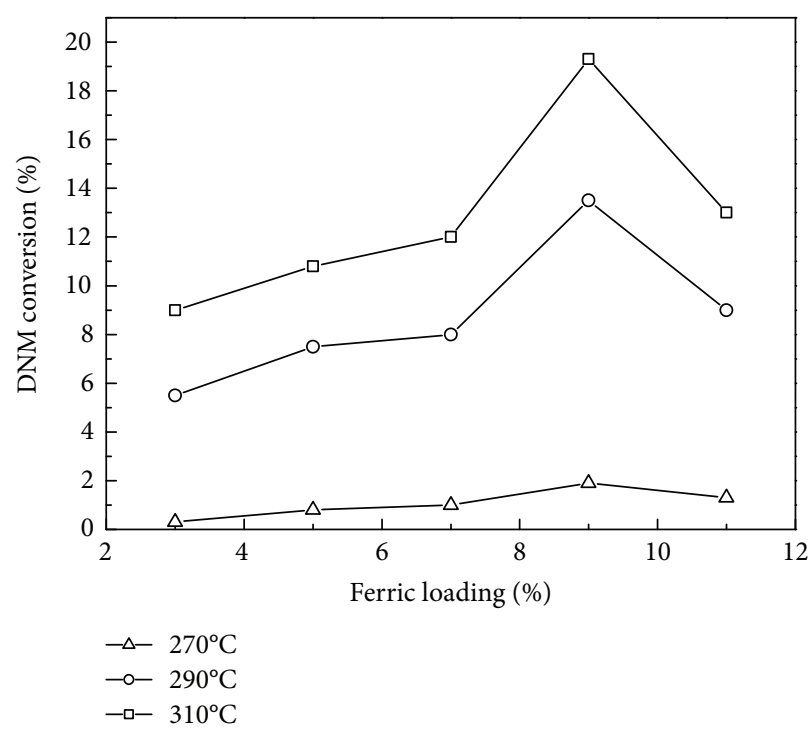

FIGURE 1: Effect of Fe loading on DNM conversion rate.

autoclave. After replacing air for 3 times, the autoclave was pressurized to $5 \mathrm{MPa}$ with nitrogen and heated to $310^{\circ} \mathrm{C}$ within $15 \mathrm{~min}$. The autoclave was cooled to room temperature in an ice-water bath after being kept at $310^{\circ} \mathrm{C}$ for $1 \mathrm{~h}$. The reaction mixture was taken out and filtered through a $0.8 \mu \mathrm{m}$ membrane filter, and the residue from GBC (RGBC) was dried in vacuum at $80^{\circ} \mathrm{C}$ for $6 \mathrm{~h}$.

The RGBC ( $1 \mathrm{~g}), \mathrm{Fe}_{2} \mathrm{~S}_{3} / \mathrm{AC}-\mathrm{T}$ catalyst $(0.5 \mathrm{~g})$, and cyclohexane $(50 \mathrm{~mL})$ were put into a $100 \mathrm{~mL}$ stainless, magnetically stirred autoclave. After replacing air for 3 times, the autoclave was pressurized to $0.8 \mathrm{MPa}$ with hydrogen, heated to $310^{\circ} \mathrm{C}$ within $15 \mathrm{~min}$, and kept at the temperature for $1 \mathrm{~h}$. Then the autoclave was immediately cooled to room temperature in an ice-water bath. The reaction mixture was taken out from the autoclave using petrol ether as the rinse solvent and filtered through a $0.8 \mu \mathrm{m}$ membrane filter. The filtrate was concentrated by evaporating the solvents using a rotary evaporator and then analyzed with a Hewlett-Packard 6890/5973 GC/MS.

\section{Results and Discussion}

Figure 1 shows the dependence of DNM conversion on the $\mathrm{Fe}$ loading of $\mathrm{Fe}_{2} \mathrm{~S}_{3} / \mathrm{AC}-\mathrm{T}$. At $270^{\circ} \mathrm{C}$, the conversion rate of DNM over $\mathrm{Fe}_{2} \mathrm{~S}_{3} / \mathrm{AC}-\mathrm{T}$ with various Fe loading was below $1 \%$. When the reaction temperature increased to 290 or $310^{\circ} \mathrm{C}$, with the increases of Fe loading ( $3 \%$ to $9 \%$ ), the DNM conversion rate increased and reached a maximum of $13.5 \%$ at $290^{\circ} \mathrm{C}$ and $19.3 \%$ at $310^{\circ} \mathrm{C}$. With further increase of Fe loading, the DNM conversion rate decreased to $9 \%$ at $290^{\circ} \mathrm{C}$ and $13 \%$ at $310^{\circ} \mathrm{C}$. The results indicated that $9 \%$ of Fe loading is appropriate for the catalyst and excessive ferric sulfide may result in a decrease of specific surface area, which in turn reduce the catalytic efficiency. The hydrocracking of DNM is an endothermic reaction, and higher temperature is favorable for the reaction. It can be seen in Figure 1 that a high DNM conversion was got under a mild condition (reaction temperature of $310^{\circ} \mathrm{C}$ ). 


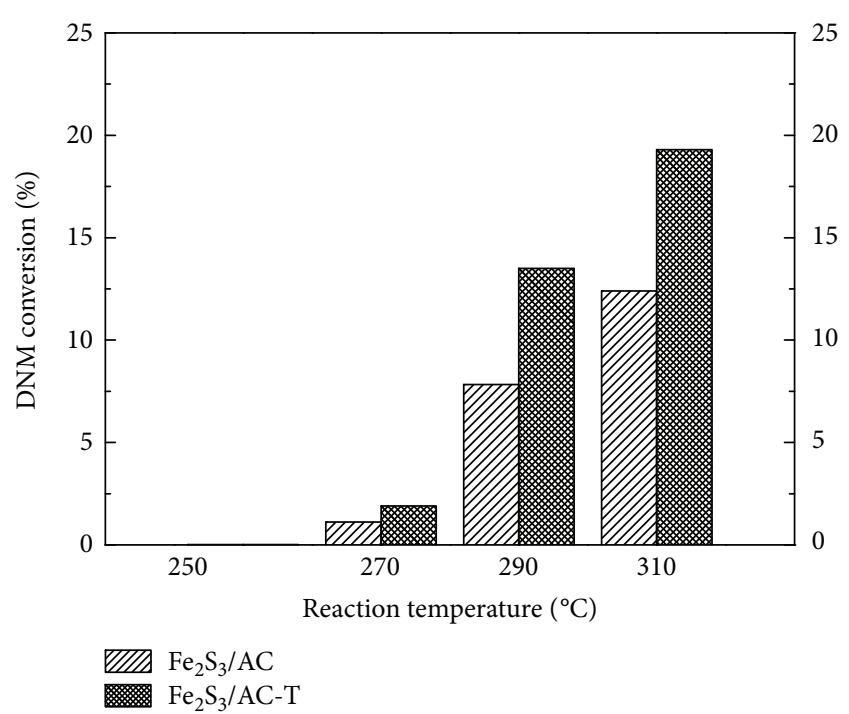

FIGURE 2: DNM conversion rates with two kinds of catalysts at different temperatures.

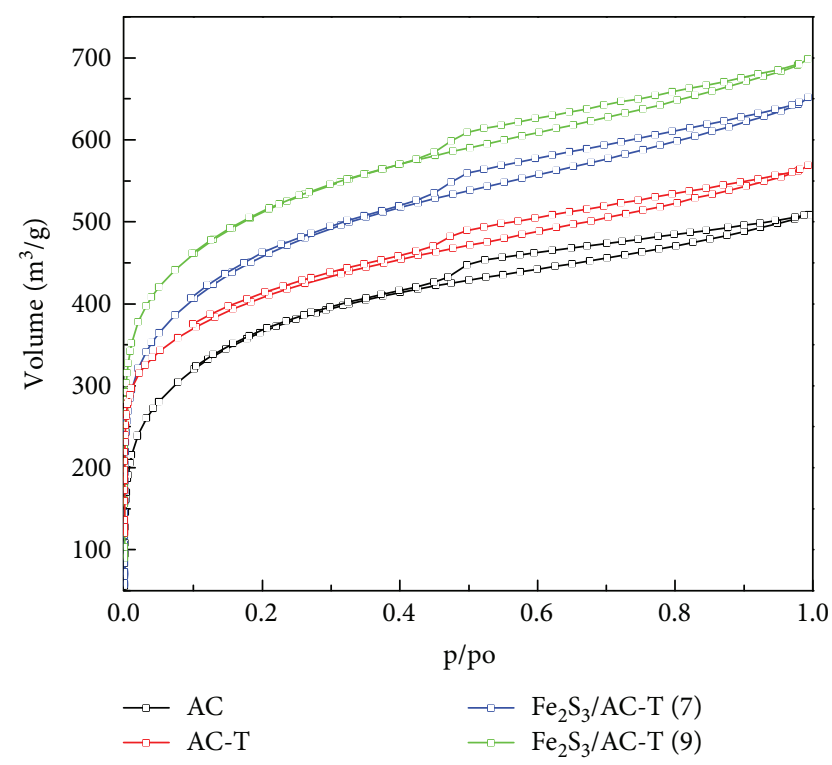

FIGURE 3: $\mathrm{N}_{2}$ adsorption-desorption isotherms of supports and catalysts.

The catalytic activities of the catalysts $\mathrm{Fe}_{2} \mathrm{~S}_{3} / \mathrm{AC}$ (9) and $\mathrm{Fe}_{2} \mathrm{~S}_{3} / \mathrm{AC}-\mathrm{T}$ (9) were compared in Figure 2, which summarizes the DNM conversions under different reaction temperatures. At $250^{\circ} \mathrm{C}$, the DNM conversion was close to zero. As the reaction temperature rised to $270^{\circ} \mathrm{C}$, the DNM conversion over $\mathrm{Fe}_{2} \mathrm{~S}_{3} / \mathrm{AC}$ (9) and $\mathrm{Fe}_{2} \mathrm{~S}_{3} / \mathrm{AC}-\mathrm{T}$ (9) were $1.12 \%$ and $1.9 \%$, respectively. With further increase of reaction temperature to $290^{\circ} \mathrm{C}$, the DNM conversion increased greatly, $7.85 \%$ over $\mathrm{Fe}_{2} \mathrm{~S}_{3} / \mathrm{AC}$ (9) and $13.5 \%$ over $\mathrm{Fe}_{2} \mathrm{~S}_{3}$ /AC-T (9), respectively. At $310^{\circ} \mathrm{C}$, the DNM conversion reached $12.4 \%$ and $19.3 \%$ over $\mathrm{Fe}_{2} \mathrm{~S}_{3} / \mathrm{AC}$ (9) and $\mathrm{Fe}_{2} \mathrm{~S}_{3}$ /AC-T (9), respectively.

It is believed that the $\mathrm{H}_{2} \mathrm{~S}$ species, generated by ferric sulfate and hydrogen gas under enhanced temperature and

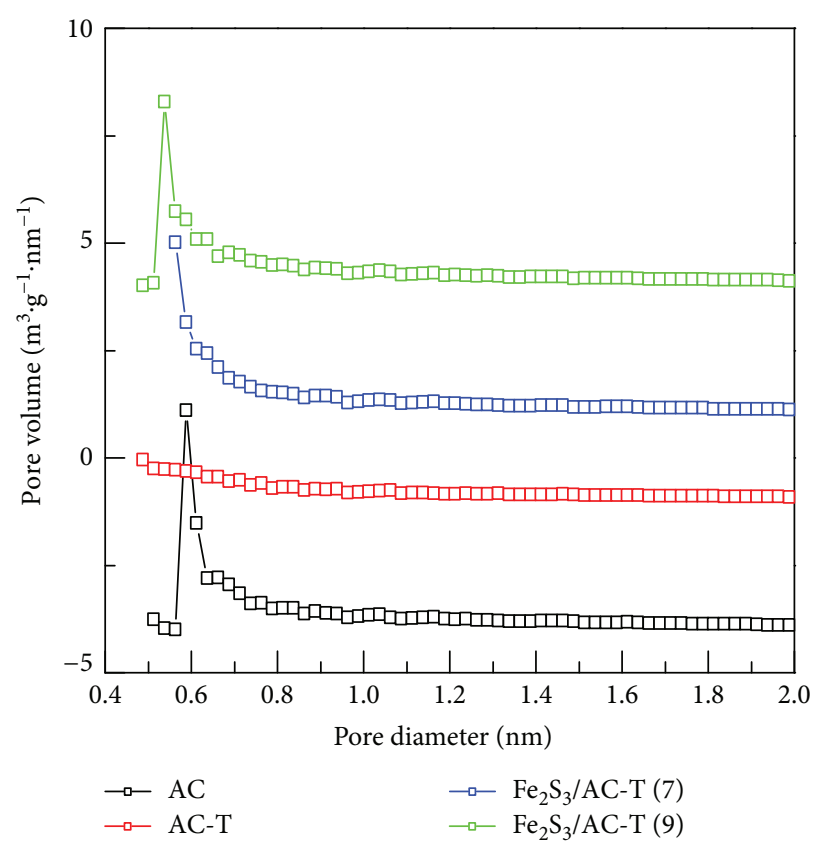

(a)

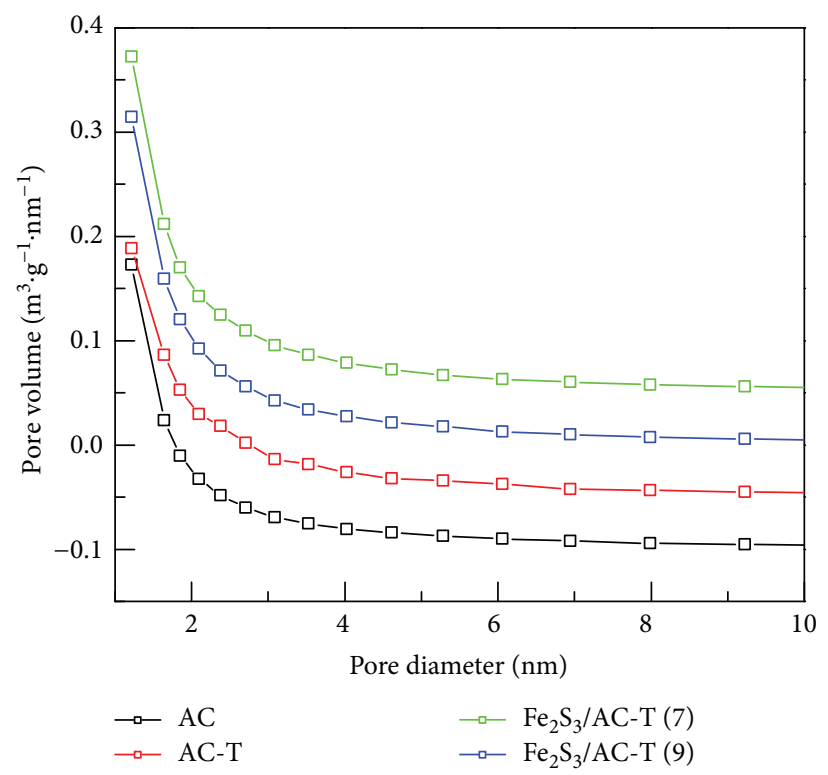

(b)

Figure 4: Micropore-size distribution (a) and mesopore-size distribution (b) of carriers and catalysts.

pressure, further react with the C-C-bridged bonds of DNM to form naphthalene and methyl naphthalene. In our study, the support AC-T was obtained by impregnating the AC to sulfuric acid solution, and the catalyst $\mathrm{Fe}_{2} \mathrm{~S}_{3} / \mathrm{AC}-\mathrm{T}$ was coated with a layer of acid sites. The acid sites are helpful to the cleavage of C-C-bridged bonds. The catalyst $\mathrm{Fe}_{2} \mathrm{~S}_{3} /$ AC- $\mathrm{T}$ was more active than the $\mathrm{Fe}_{2} \mathrm{~S}_{3} / \mathrm{AC}$, which could be ascribed to the synergy effects of ferric sulfate and acid sites in the catalyst.

$\mathrm{N}_{2}$ adsorption-desorption isotherms of supports and catalysts are shown in Figure 3. Those of AC, AC-T, $\mathrm{Fe}_{2} \mathrm{~S}_{3} /$ 
TABLE 1: The surface properties of AC support and the catalysts.

\begin{tabular}{|c|c|c|c|c|c|}
\hline Samples & $\mathrm{SSA}\left(\mathrm{m}^{2} / \mathrm{g}\right)$ & $\mathrm{TPV}\left(\mathrm{cm}^{3} / \mathrm{g}\right)$ & $V \operatorname{mic}\left(\mathrm{cm}^{3} / \mathrm{g}\right)$ & $D_{\mathrm{BJH}}(\mathrm{nm})$ & $D_{\mathrm{HK}}(\mathrm{nm})$ \\
\hline $\mathrm{AC}$ & 1485.7 & 0.8625 & 0.7259 & 2.3221 & 0.5875 \\
\hline AC-T & 1017 & 0.691 & 0.5264 & 2.7178 & 0.51 \\
\hline $\mathrm{Fe}_{2} \mathrm{~S}_{3} / \mathrm{AC}-\mathrm{T}(7)$ & 1465.7 & 0.9389 & 0.7538 & 2.5623 & 0.5375 \\
\hline $\mathrm{Fe}_{2} \mathrm{~S}_{3} / \mathrm{AC}-\mathrm{T}$ (9) & 1508.1 & 0.9581 & 0.7654 & 2.5412 & 0.6125 \\
\hline
\end{tabular}

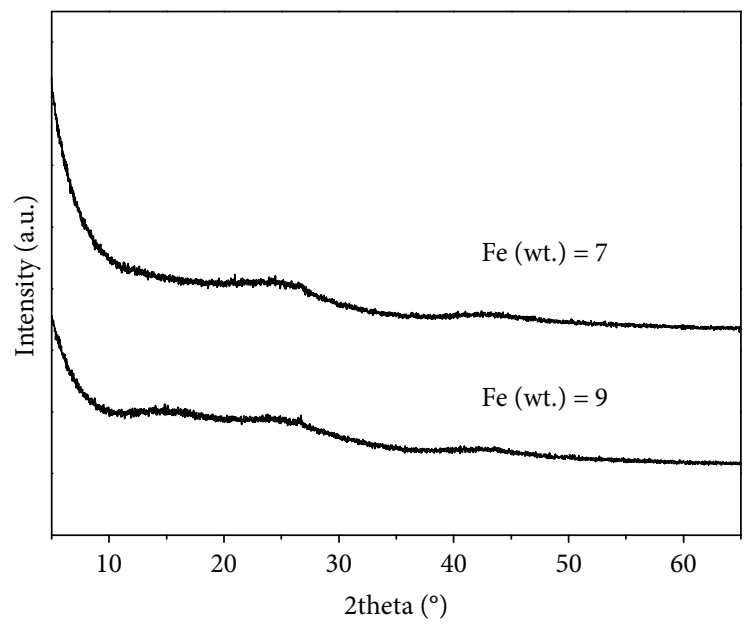

Figure 5: XRD patterns of the catalysts.

AC-T (7) and $\mathrm{Fe}_{2} \mathrm{~S}_{3} / \mathrm{AC}-\mathrm{T}$ (9) exhibited a mixture of type and type isotherms, with a wider knee exhibited at relative pressure $(\mathrm{p} / \mathrm{p} 0)<0.1$. This indicated wider micropores. An obvious capillary condensation step (hysteresis loop) at $\mathrm{p} / \mathrm{p} 0>0.4$ indicated that a considerable amount of mesoporous was also present. Mesopore- and micropore-size distributions are shown in Figures 4(a) and 4(b), respectively, and the specific surface area, total pore volume, and pore diameter of the support $\mathrm{AC}$ and the catalyst $\mathrm{Fe}_{2} \mathrm{~S}_{3} / \mathrm{AC}-\mathrm{T}$ are listed in Table 1. It can be seen that $\mathrm{AC}$ has a high specific surface area and a high percentage of micropores and the pore-size distribution was predominantly $0.5-0.8 \mathrm{~nm}$. After treated by sulfuric acid, the specific surface area and total volume of AC-T decreased about $30 \%$ and $18 \%$, respectively. The micropore size becomes nonuniform and has a wide range of distribution. Compare to the support AC-T, the $\mathrm{Fe}_{2} \mathrm{~S}_{3} / \mathrm{AC}-\mathrm{T}$ catalysts have a significantly higher specific surface area and total pore volume. It may be ascribed to the loose structure of ferric sulfate on the support. A certain amount of micropores was also formed during impregnation. The values of specific surface area and total pore volume reach the maximum at the Fe loading of $9 \mathrm{wt} . \%$. Combined with the catalytic performance exhibited in Figures 1 and 2, the optimal loading of Fe is $9 \mathrm{wt} . \%$.

The XRD patterns of the catalyst $\mathrm{Fe}_{2} \mathrm{~S}_{3} / \mathrm{AC}-\mathrm{T}$ with different ferric sulfate loading are shown in Figure 5. The broad diffraction peak showed between $2 \theta=20 \sim 30^{\circ}$ is ascribed to the support AC. It is obvious that the catalyst only exhibited the diffraction peak of support AC. The absence of diffraction peaks of ferric substance can be ascribed to its well dispersion on the AC surface.

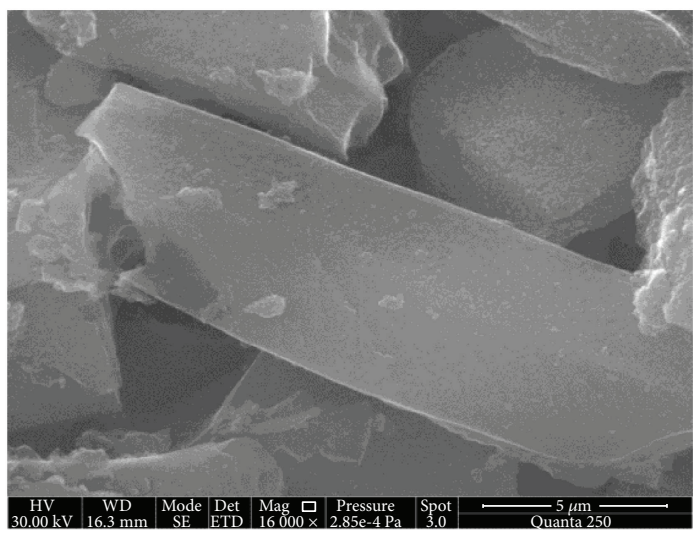

(a)

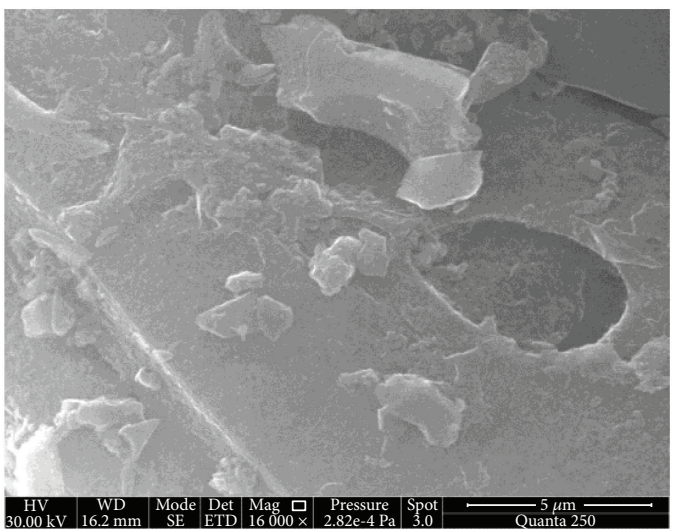

(b)

Figure 6: SEM images of AC (a) and $\mathrm{Fe}_{2} \mathrm{~S}_{3} / \mathrm{AC}-\mathrm{T}$ (b).

As Figure 6 displays, the surface of AC support is smooth, and the surface of catalyst $\mathrm{Fe}_{2} \mathrm{~S}_{3} / \mathrm{AC}-\mathrm{T}$ (9) is rough. There are irregular bulks adhered to the AC surface. Combined with the XRD results, the bulks of ferric sulfate are well dispersed on the AC surface.

Total ion chromatogram of the filtrate of reaction mixture from catalytic hydroconversion of RGBC is shown in Figure 7. 18 compounds were identified and listed in Table 2. Five arenes and 13 alkanes were identified. It indicated that the $\mathrm{Fe}_{2} \mathrm{~S}_{3}$ /AC-T significantly catalyzed the hydroconversion of RGBC and forms GC/MS-detectable species.

\section{Conclusions}

Ascribed to the synergy effects of ferric sulfate and acid sites, the $\mathrm{Fe}_{2} \mathrm{~S}_{3} / \mathrm{AC}$-T exhibited a benign catalytic performance for DNM hydrocracking. 

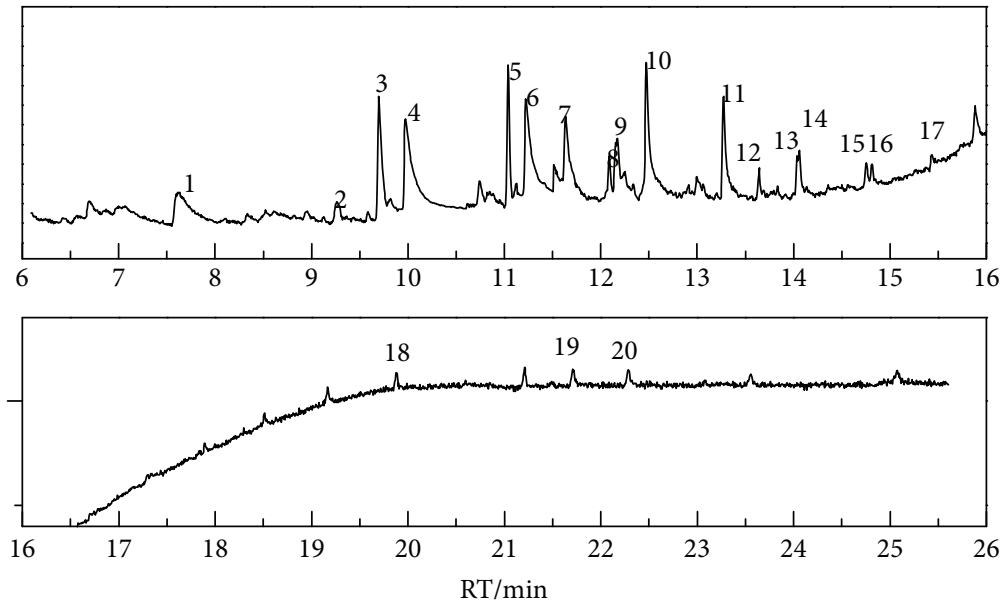

FIGURE 7: Total ion chromatogram of the filtrate of reaction mixture.

TABLE 2: The compounds detected in the reaction mixture.

\begin{tabular}{|c|c|c|}
\hline Peaks & $\mathrm{RT}(\min )$ & Compounds \\
\hline \multicolumn{3}{|l|}{ Arenes } \\
\hline 1 & 7.63 & 1,2,3-Trimethyl-benzene \\
\hline 2 & 9.27 & 1,2,3,4-Tetramethyl-benzene \\
\hline 3 & 9.7 & 1,2,3,4-Tetrahydro-naphthalene \\
\hline 4 & 9.98 & Naphthalene \\
\hline 6 & 11.23 & 2-Methyl-naphthalene \\
\hline \multicolumn{3}{|l|}{ Alkane } \\
\hline 5 & 11.04 & Bicyclohexyl \\
\hline 7 & 11.64 & Tetradecane \\
\hline 8 & 12.09 & 1-Cyclohexylmethyl-4-methyl-cyclohexane \\
\hline 9,16 & 12.16 & 2,6,10-Trimethyl-dodecane \\
\hline 10 & 12.48 & Tridecane \\
\hline 11 & 13.27 & Hexadecane \\
\hline 12 & 13.64 & 5-Ethyl-decane5 \\
\hline 13,19 & 14.03 & Octadecane \\
\hline 14 & 14.06 & 2,6,10-Trimethyl-pentadecane \\
\hline 15,18 & 14.75 & Eicosane \\
\hline 17 & 15.44 & Pentadecane \\
\hline 20 & 22.68 & Nonadecane \\
\hline
\end{tabular}

The $\mathrm{Fe}_{2} \mathrm{~S}_{3}$ /AC-T significantly catalyzed the hydroconversion of RGBC and forms GC/MS-detectable species. Five arenes and 13 alkanes were identified in the filtrate of reaction mixture.

\section{Conflicts of Interest}

The authors declare that they have no conflicts of interest.

\section{Acknowledgments}

This work was supported by National Natural Science Foundation of China (21506249) and the Fundamental Research Funds for the Central Universities (China University of Mining and Technology, 2014QNA19).

\section{References}

[1] H. H. Schobert and C. Song, "Chemicals and materials from coal in the 21st century," Fuel, vol. 81, no. 1, pp. 15-32, 2002.

[2] H. F. Shui, Z. P. Cai, and C. B. Xu, "Recent advances in direct coal liquefaction,” Energies, vol. 3, no. 2, pp. 155-170, 2010.

[3] H. R. Zhou, S. Y. Yang, H. H. Xiao, Q. H. Yang, and L. Gao, "Modeling and techno-economic analysis of shale-to-liquid and coal to liquid fuels processes," Energy, vol. 109, pp. 201210, 2016.

[4] Z. Y. Luo and M. Agraniotis, "Coal-to-liquids and polygeneration using low rank coals," in Low Rank Coals for power generation, Fuel and Chemical Production, pp. 241-268, Woodhead Publishing, Duxford, UK, 2017.

[5] K. Miura, "Mild conversion of coal for producing valuable chemicals," Fuel Processing Technology, vol. 62, no. 2-3, pp. 119-135, 2000.

[6] Z. P. Lei, S. F. Zhang, W. Lian, H. F. Shui, and S. B. Ren, "Study on mild hydrogenation of Xianfeng lignite in ionic liquid," Journal of Fuel Chemistry and Technology, vol. 41, no. 8, pp. 922-927, 2013.

[7] J. C. Yan, Z. Q. Bai, P. Hao, J. Bai, and W. Li, "Comparative study of low temperature pyrolysis and solvent treatment on upgrading and hydro-liquefaction of brown coal," Fuel, vol. 199, no. 1, pp. 598-605, 2017.

[8] X. Y. Wei, E. Ogata, and E. Niki, "Catalyses of Fe and $\mathrm{FeS}_{2}$ on the reaction of di(1-naphthyl)methane," Chemistry Letters, vol. 20, no. 12, pp. 2199-2202, 1991.

[9] K. Hirano, M. Kouzu, T. Okada, M. Kobayashi, N. Ikenaga, and T. Suzuki, "Catalytic activity of iron compounds for coal liquefaction,” Fuel, vol. 78, no. 15, pp. 1867-1873, 1999.

[10] T. Kaneko, K. Tazawa, N. Okuyama, M. Tamura, and K. Shimasaki, "Effect of highly dispersed ion catalyst on direct liquefaction of coal," Fuel, vol. 79, no. 3-4, pp. 263-271, 2000.

[11] Z. H. Ni, Z. M. Zong, L. F. Zhang et al., "Reactivities of di(1-naphthyl)methane toward hydrocracking over Ni-S," Energy \& Fuels, vol. 16, pp. 1154-1159, 2002.

[12] Z. C. Wang, H. F. Shui, D. X. Zhang, and J. S. Gao, "A comparison of $\mathrm{FeS}, \mathrm{FeS}+\mathrm{S}$ and solid superacid catalytic properties for coal hydro-liquefaction," Fuel, vol. 86, no. 5-6, pp. 835-842, 2007. 
[13] Z. C. Wang, H. F. Shui, X. P. Gu, and J. S. Gao, "Study on the direct liquefaction reactivity of Shenhua coal catalyzes by $\mathrm{SO}_{4}{ }^{2-} / \mathrm{ZrO}_{2}$ solid acid," Journal of Fuel Chemistry and Technology, vol. 38, no. 3, pp. 257-263, 2010.

[14] S. G. Kang, Z. M. Zong, H. F. Shui, Z. C. Wang, and X. Y. Wei, "Comparison of catalytic hydroliquefaction of Xiaolongtan lignite over $\mathrm{FeS}, \mathrm{FeS}+\mathrm{S}$ and $\mathrm{SO}_{4}{ }^{2-} / \mathrm{ZrO}_{2}$," Energy, vol. 36, no. 1, pp. 41-45, 2011.

[15] X. Fan, G. F. Liu, Z. M. Zong et al., "Mechanism for catalytic hydrodenitrogenation of isoquinoline," Fuel Processing Technology, vol. 106, pp. 661-665, 2013.

[16] C. Y. Wang, J. Mu, and C. L. Wu, "Research and development of direct coal liquefaction catalyst," Coal Science and Technology, vol. 4, pp. 24-25, 1998.

[17] X. Li, S. Hu, L. Jin, and H. Hu, "Role of iron-based catalyst and hydrogen transfer in direct coal liquefaction," Energy \& Fuels, vol. 22, no. 2, pp. 1126-1129, 2008.

[18] S. H. Weng, Y. Q. Wu, J. S. Gao, C. G. Zhao, and Z. Wu, "Mossbauer spectroscopic study of iron catalyst in coal hydroliquefaction-II. On the transformation and the action mechanism of iron sulphide in hydrogenation," Journal of Fuel Chemistry and Technology, vol. 18, pp. 97-102, 1990.

[19] L. J. Wang, Z. D. Cui, and S. K. Lui, "The application of Mossbauer spectroscopy to the study of coal catalytic liquefaction I. The transformation of iron catalysts during liquefaction," Journal of Fuel Chemistry and Technology, vol. 18, pp. 268272, 1990.

[20] X. M. Yue, X. Y. Wei, B. Sun, Y. H. Wang, Z. M. Zong, and Z. W. Liu, "Solid superacid-catalyzed hydroconversion of an extraction residue from Lingwu bituminous coal," International Journal of Mining Science and Technology, vol. 22, no. 2, pp. 251-254, 2012.

[21] X. M. Yue, X. Y. Wei, B. Sun et al., "A new solid acid for specifically cleaving the $\mathrm{C}_{\mathrm{ar}}-\mathrm{C}_{\text {alk }}$ bond in di(1-naphthyl)methane," Applied Catalysis A: General, vol. 425-426, pp. 7984,2012 

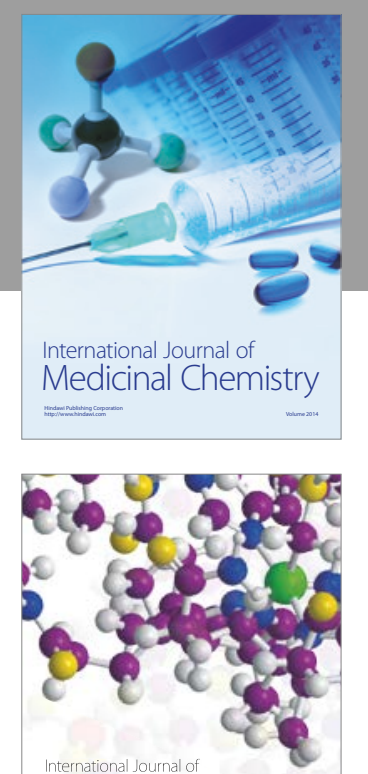

Carbohydrate Chemistry

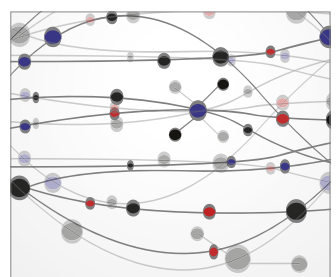

The Scientific World Journal
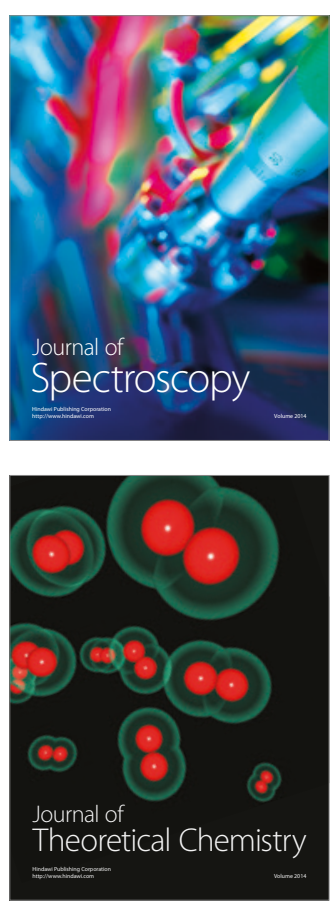
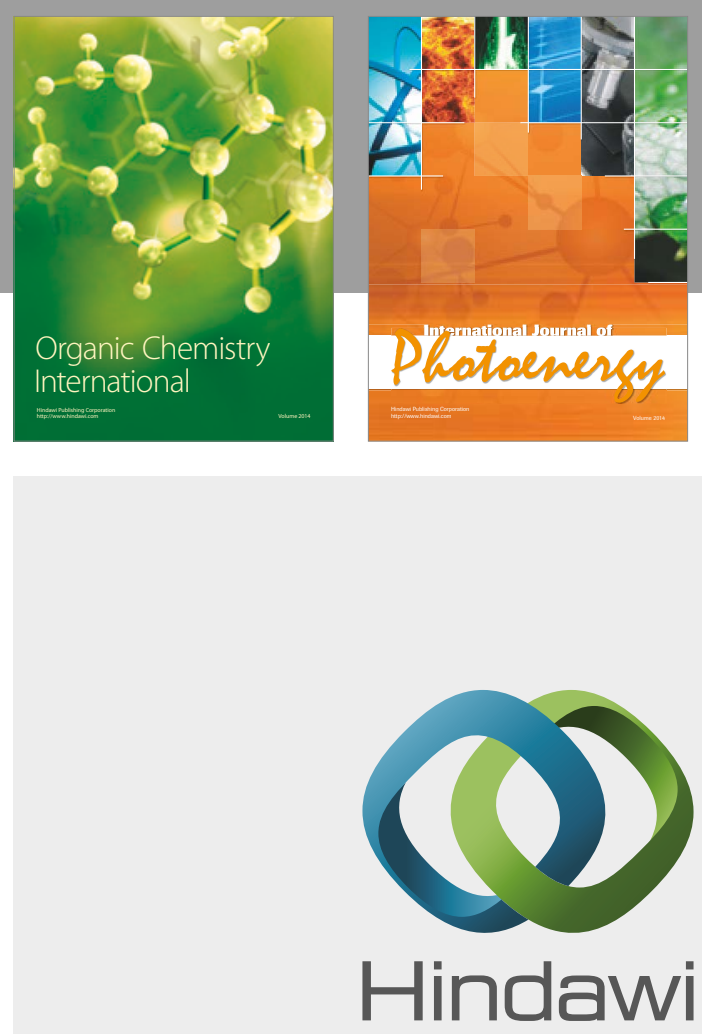

Submit your manuscripts at

https://www.hindawi.com

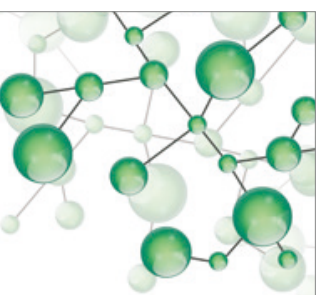

International Journal of

Inorganic Chemistry

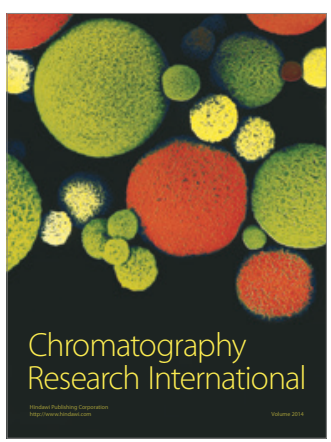

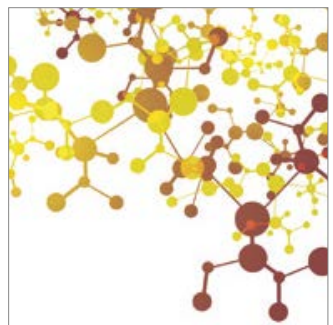

Applied Chemistry
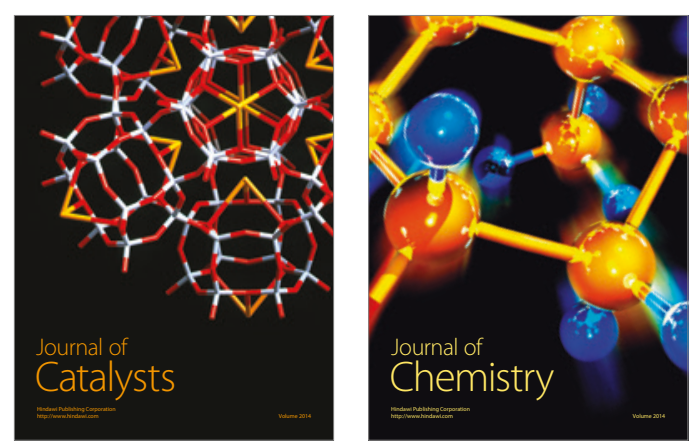
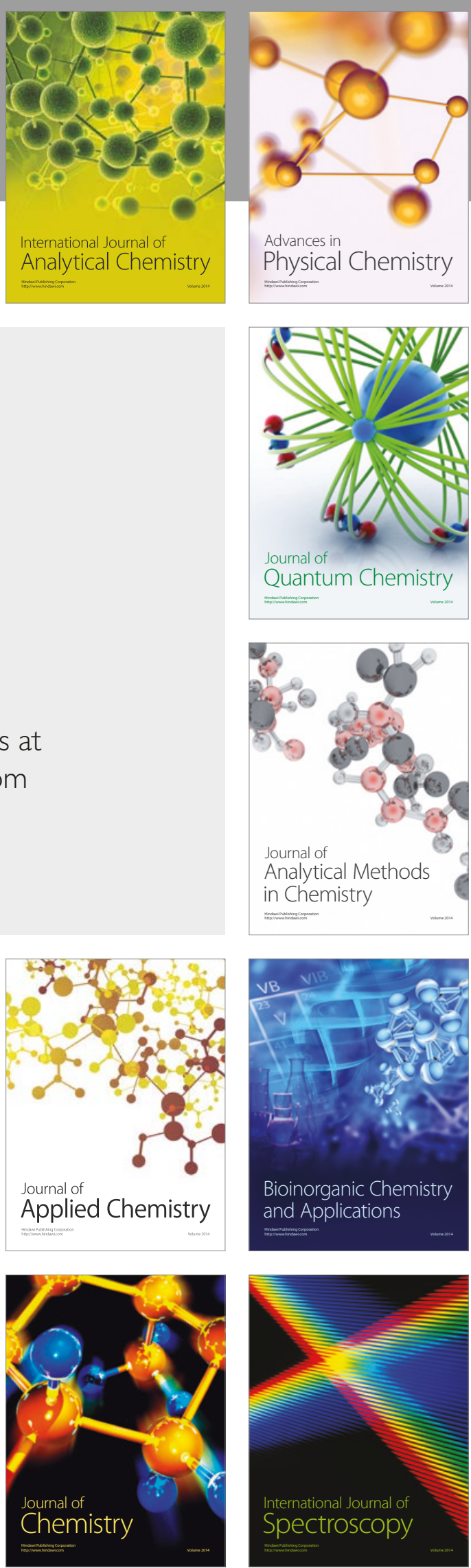